\title{
Penentuan Potensi Wisata Prioritas melalui Pendekatan Community-Based Tourism di Desa Wisata Teritip Kota Balikpapan
}

\author{
Determining of Priority Tourism Potentials \\ through Community-Based Tourism Approach \\ in Desa Wisata Teritip, Balikpapan City
}

\begin{abstract}
Kiki Amalia Putri ${ }^{1 *}$, Ajeng Nugrahaning Dewanti ${ }^{1} \&$ Mohammad Muntaha $^{2}$
${ }^{1}$ Program Studi Perencanaan Wilayah dan Kota, Jurusan Teknik Sipil dan Perencanaan, Institut Teknologi Kalimantan, Jl. Soekarno-Hatta Km. 15, Kalimantan Timur 76127; ${ }^{2}$ Program Studi Teknik Sipil, Jurusan Teknik Sipil dan Perencanaan, Institut Teknologi Kalimantan, Jl. Soekarno-Hatta Km. 15, Kalimantan Timur 76127;

"Penulis Korespondensi.e-mail:08131003@itk.ac.id

(Diterima: 18 Mei 2017; Disetujui: 21 Oktober 2017)
\end{abstract}

\begin{abstract}
Desa Wisata Teritip (Teritip Tourism Village) is one of the new destinations of Balikpapan City which has 12 potential points for tourism, including the potential of site attraction (nature's beauty) and the potential of event attraction (community culture and tourism activities). However, these potentials has not been utilized and developed optimally by the local community up to now. The development is constrained by the lack of community involvement in managing the tourism village. The purpose of this study was to identify priority tourism potentials to be developed through community-based approaches in order to put the role of the local community as subject and object of the development of the village. This study uses rationalistic approach with a qualitative descriptive method. The analysis technique used to answer the research objectives, are: on the first stage, content analysis was used to analyze the potential tourism attractions to be developed; and followed by the second stage, a descriptive qualitative analysis to identify potential tourism attraction priorities for development by emphasizing the role of local communities.

The result obtained is that the three factors of attractiveness: nature's beauty, community culture and tourism activities, has the potential to be develop through community-based approaches and there are 10 potential tourism priorities to be developed, which covers physical, socio-cultural, and supporting tourism objects.
\end{abstract}

Keywords: tourism potential, rural tourism, community-based tourism

\begin{abstract}
ABSTRAK
Desa Wisata Teritip merupakan salah satu destinasi baru Kota Balikpapan yang memiliki 12 potensi titik kepariwisataan. Potensi wisata yang ada beragam, baik potensi site attraction (keindahan alam) maupun potensi event attraction (budaya masyarakat dan kegiatan wisata). Akan tetapi, hingga saat ini potensi tersebut belum dimanfaatkan dan dikembangkan secara optimal oleh masyarakat lokal. Pengembangan kawasan desa wisata ini masih terkendala keterlibatan masyarakat yang minim untuk mengelola desa wisata. Tujuan penelitian ini adalah untuk mengidentifikasi potensi wisata prioritas untuk dikembangkan melalui pendekatan community-based tourism guna menempatkan peran masyarakat lokal sebagai subjek sekaligus objek dalam pengembangan desa. Penelitian ini
\end{abstract}


menggunakan pendekatan rasionalistik dengan jenis deskriptif kualitatif. Teknik analisis yang digunakan untuk menjawab tujuan penelitian, antara lain pada tahap pertama digunakan analisis konten untuk menganalisis daya tarik yang potensial untuk dikembangkan dan dilanjutkan dengan tahap kedua yang menggunakan analisis deskriptif kualitatif untuk mengidentifikasi potensi daya tarik wisata yang prioritas untuk dikembangkan dengan mengutamakan peran masyarakat lokal. Hasil yang diperoleh adalah ketiga faktor daya tarik yang ada, baik keindahan alam, budaya masyarakat, maupun kegiatan wisata, memiliki potensi untuk dikembangkan melalui pendekatan community-based tourism dan terdapat sepuluh potensi wisata prioritas untuk dikembangkan, yang tersebar dalam komponen fisik, sosial budaya, maupun objek wisata pendukung.

Kata Kunci: potensi wisata, desa wisata, community-based tourism

\section{PENDAHULUAN}

Sektor pariwisata dapat menjadi penentu dan katalisator untuk mengembangkan pembangunan sektor lainnya secara bertahap (Mujanah et al., 2016). Pariwisata alam cenderung berkembang pesat dibandingkan dengan jenis pariwisata lain. Produk wisata konvensional mulai ditinggalkan dan wisatawan beralih pada wisata yang lebih menghargai alam, budaya, dan atraksi spasial (Susyanti, 2013). Salah satu pendekatan pengembangan pariwisata alam adalah desa wisata. Desa wisata merupakan suatu bentuk integrasi antara atraksi, akomodasi, dan fasilitas pendukung yang disajikan dalam suatu struktur kehidupan masyarakat yang menyatu dengan tata cara dan tradisi yang berlaku (Astuti, 2012).

Kelurahan Teritip merupakan salah satu wilayah administratif di Kota Balikpapan yang memiliki potensi pariwisata cukup beragam. Ada sekitar 12 titik kepariwisataan di kawasan tersebut, yaitu berupa kebun penelitian, mangrove, pantai, tambak, ternak, sawah, kebun buah dan sayuran serta beberapa objek wisata pendukung lainnya. Potensi pariwisata ini perlu dimanfaatkan secara optimal agar berdampak positif bagi masyarakat lokal. Salah satu upaya pemerintah dalam mengembangkan kawasan tersebut adalah dengan menjadikannya suatu destinasi wisata baru dengan konsep desa wisata. Desa Wisata Teritip diresmikan sejak tahun 2011 dan akan dikembangkan sebagai salah satu destinasi wisata alam andalan Kota Balikpapan sesuai dengan arahan Rencana Tata Ruang Wilayah Kota Balikpapan tahun 2012 hingga 2032.
Kondisi eksisting yang ada menunjukkan bahwa pengembangan desa wisata masih difokuskan pada wilayah Gunung Binjai sehingga berdampak pada pemanfaatan potensi wisata lain yang belum optimal. Hal ini dikarenakan belum semua masyarakat lokal terlibat langsung dalam pengembangan desa wisata. Pemanfaatan potensi wisata tersebut juga berpengaruh terhadap atraksi atau daya tarik yang mampu ditawarkan kepada wisatawan yang berkunjung. Nurdiyanto (2015) mengemukakan bahwa atraksi sebagai salah satu unsur penting dalam menunjang desa wisata yang memungkinkan adanya interaksi wisatawan sebagai partisipasi aktif dalam kegiatan yang spesifik. Jika masyarakat lokal tidak turut aktif dalam mengelola berbagai potensi yang tersedia, tentu pengembangan desa wisata ini tidak akan berjalan dengan lancar. Masyarakat diajak untuk berperan serta dan didorong untuk berpartisipasi karena dianggap mengetahui permasalahan dan kebutuhan mereka serta memahami tentang keadaan lingkungan, sosial, dan ekonomi wilayahnya (Adisasmita, 2013). Adanya sumber daya dan keunikan komunitas lokal merupakan unsur penggerak utama kegiatan wisata sehingga semestinya kepariwisataan harus dipandang sebagai kegiatan yang berbasis paa komunitas (Murphy dalam Rahayu, 2015). Oleh karena itu, dibutuhkan adanya upaya untuk mengenali potensi desa sebagai langkah awal dalam mengembangkan Desa Wisata Teritip yang dilakukan secara mandiri oleh masyarakat lokal melalui pendekatan community-based tourism. Pendekatan tersebut sebagai pertimbangan pokok dalam menumbuhkembangkan kapasitas dan kapabilitas pada masyarakat untuk dapat 
meningkatkan pelayanan sekaligus merealisasikan peran sentral masyarakat dalam aktivitas pembangunan kepariwisataan sesuai dengan harapan dan kemampuan yang dimiliki (Beeton, 2006).

Munculnya fenomena community-based tourism merupakan kritik atas pengelolaan wisata yang dilaksanakan tanpa melibatkan masyarakat dan dipandang kurang mampu memberdayakan masyarakat. Pendekatan ini merupakan konsep pengelolaan kepariwisataan dengan mengedepankan partisipasi aktif masyarakat dan mampu memberikan manfaat bagi masyarakat, meliputi peningkatan kesejahteraan, perlindungan terhadap lingkungan serta kehidupan sosial budaya masyarakat setempat (Purmada et al., 2016).

Berdasarkan latar belakang permasalahan tersebut maka penelitian ini dilakukan dengan tujuan untuk mengidentifikasi potensi wisata prioritas Desa Wisata Teritip untuk dikembangkan melalui pendekatan community-based tourism berdasarkan daya tarik yang ada.

\section{METODOLOGI}

\section{Pendekatan Penelitian}

Penelitian ini menggunakan pendekatan rasionalistik yang merupakan gabungan teori (theoretical analytic) dan kebenaran empirik (empirical analytic) (Ikhwanuddin, 2015). Pendekatan analisis teori yang digunakan berkaitan dengan jenis potensi yang ada dalam konsep desa wisata dengan penerapan communitybased tourism, baik site attraction maupun event attraction, serta dikaitkan dengan fakta-fakta empiris yang terjadi di wilayah penelitian.

\section{Jenis Penelitian}

Jenis penelitian yang digunakan adalah deskriptif kualitatif. Penelitian deskriptif kualitatif mengarah kepada pendeskripsian secara rinci dan mendalam mengenai potret kondisi eksisting yang terjadi di wilayah penelitian (Suhamdani, 2013).

\section{Variabel Penelitian}

Penelitian ini difokuskan pada pembahasan terkait potensi daya tarik wisata yang ada di Desa
Wisata Teritip dengan variabel berupa site attraction (keindahan alam) dan event attraction (budaya masyarakat dan kegiatan wisata).

\section{Metode Pengumpulan Data}

Data yang digunakan pada penelitian ini adalah data primer dan data sekunder. Data primer diperoleh melalui pengamatan langsung dan wawancara, sedangkan data sekunder diperoleh dari kajian literatur dan dokumen instansi terkait seperti Bappeda Kota Balikpapan dan Disporabudpar Kota Balikpapan.

\section{Populasi dan Sampel Penelitian}

Penentuan populasi dan sampel penelitian menggunakan teknik sampling non probabilistic yang merupakan teknik pengambilan sampel yang tidak memberikan peluang yang sama bagi anggota populasi untuk dipilih menjadi sampel (Kountur dalam Rahayu, 2015). Populasi pada penelitian ini terdiri dari pihak pemerintah, swasta, dan masyarakat. Dalam pengambilan sampel digunakan metode purposive sampling untuk mendapatkan responden berkompeten dalam pencapaian sasaran penelitian dengan menggunakan alat analisis stakeholder yang menentukan sampel berdasarkan tingkat kepentingan dan pengaruh. Jumlah sampel terpilih yaitu sebanyak 7 responden, yang meliputi Kabid Pengembangan Infrastruktur dan Perekonomian Perkotaan Bappeda Balikpapan (R1), Kabid Pariwisata Dinas Pariwisata Balikpapan (R2), Kepala Camat Balikpapan Timur (R3), Kepala Lurah Teritip (R4), dan Pengelola Desa Wisata Teritip (ketua/R5, wakil ketua/R6, sekretaris/R7).

\section{Lokasi Penelitian}

Penelitian ini mencakup satu kawasan Desa Wisata Teritip yang termasuk dalam wilayah administratif Kelurahan Teritip, Kota Balikpapan.

\section{Lingkup Pembahasan}

Penelitian ini membahas penentuan potensi prioritas Desa Wisata Teritip untuk dikembangkan melalui pendekatan community-based tourism, baik site attraction maupun event attraction. Dalam menentukan potensi tersebut prioritas 
untuk dikembangkan atau tidak, yaitu dengan melihat sejauh mana potensi tersebut telah mampu menghasilkan kegiatan atau jasa yang dapat ditawarkan kepada wisatawan serta peluang pengembangan kedepannya berdasarkan hasil wawancara dengan stakeholders dan hasil observasi lapangan.

\section{Teknik Analisis}

Teknik analisis yang digunakan untuk mencapai tujuan penelitian terdiri dari dua tahapan, yaitu analisis konten dan dilanjutkan dengan analisis deskriptif kualitatif. Berikut penjabaran mengenai kedua analisis tersebut.
Analisis Potensi Desa Wisata Teritip yang Potensial untuk Dikembangkan Berdasarkan Daya Tarik yang Ada

Analisis ini menggunakan teknik analisis konten yang dilakukan dengan cara pemberian kode pada catatan teks atau transkrip wawancara yang dilakukan kepada stakeholders. Tahap ini digunakan untuk melihat faktor daya tarik yang memiliki peluang lebih untuk dikembangkan, baik site attraction (keindahan alam) maupun event attraction (budaya masyarakat dan kegiatan wisata). Berikut tahapan dari analisis konten dalam penelitian ini.

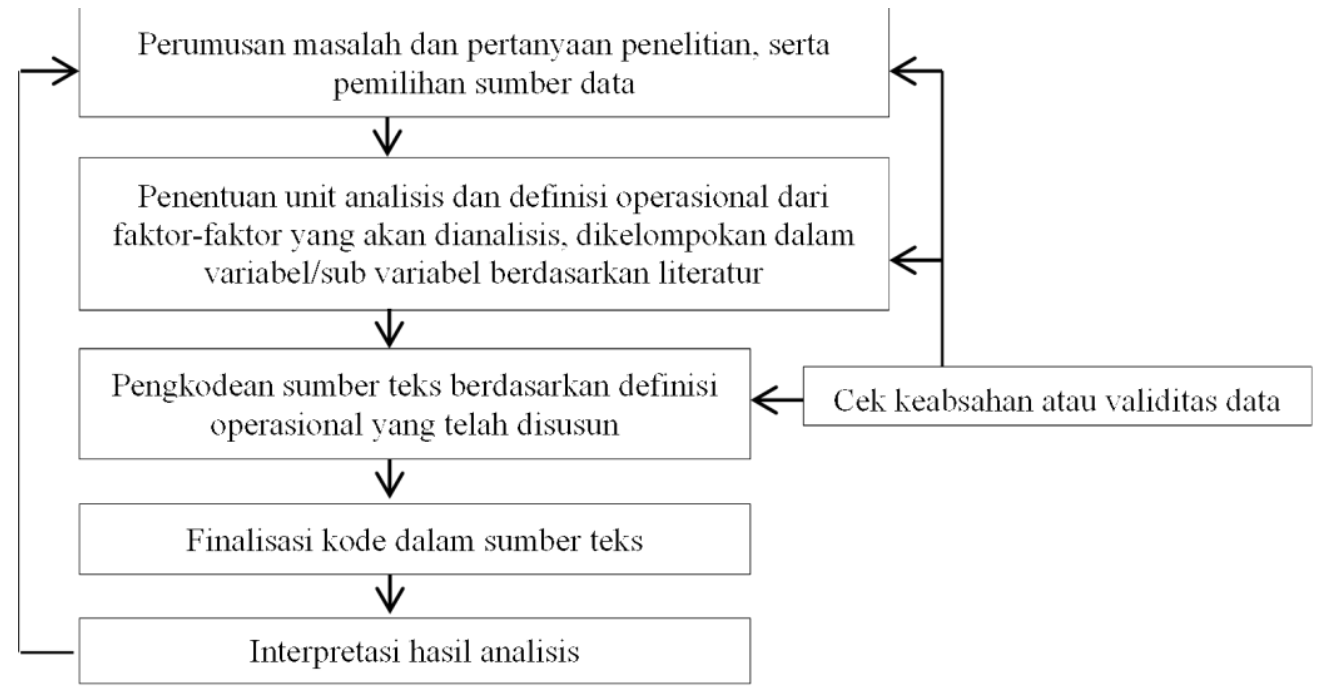

Gambar 1 Tahapan content analysis

Sumber: Hasil analisis, 2017

Untuk menguji validitas data dilakukan melalui teknik triangulasi sumber data, yaitu dengan membandingkan hasil wawancara dengan hasil observasi lapangan dan studi literatur.

\section{Identifikasi Potensi Wisata yang Prioritas untuk Dikembangkan melalui Pendekatan Community-Based Tourism}

Setelah diketahui faktor daya tarik yang potensial untuk dikembangkan, dilanjutkan dengan analisis deskriptif kualitatif untuk mendeskripsikan secara rinci mengenai kondisi potensi daya tarik yang ada di masing-masing faktor terpilih berdasarkan hasil wawancara maupun hasil observasi lapangan. Berikut tahapan dalam analisis ini.
1. Mengklasifikasi potensi yang ada menjadi tiga komponen, yaitu meliputi: (a) komponen fisik/alam (site attraction); (b) komponen sosial budaya/living culture; serta (c) objek wisata pendukung yang terdapat dalam kawasan desa. Untuk faktor kegiatan wisata tidak menjadi bagian dari klasifikasi komponen karena merupakan hasil dari pemanfaatan ketiga komponen tersebut.

2. Mengidentifikasi potensi secara spesifik yang ada di tiap komponen, baik yang belum maupun telah dikembangkan, dilihat dari hasil observasi lapangan dan hasil wawancara analisis konten.

3. Mengidentifikasi kegiatan atau jasa yang telah dihasilkan dari tiap potensi yang ada. 
4. Mengidentifikasi peluang pengembangan dari tiap potensi yang ada.

5. Memberikan kesimpulan terkait potensi yang prioritas untuk dikembangkan. Adapun klasifikasi penilaian terkait potensi daya tarik tersebut, yakni sebagai berikut.

a. Prioritas untuk dikembangkan, apabila potensi daya tarik tersebut telah mampu menawarkan kegiatan atau jasa kepada wisatawan serta memiliki peluang pengembangan kedepannya.

b. Tidak prioritas untuk dikembangkan, apabila potensi daya tarik tersebut telah mampu menawarkan jasa, namun belum memiliki peluang pengembangan kedepannya.

c. Tidak prioritas untuk dikembangkan, apabila potensi daya tarik tersebut belum mampu menawarkan jasa, tetapi memiliki peluang pengembangan kedepannya. d. Tidak prioritas untuk dikembangkan, apabila potensi daya tarik tersebut belum mampu menawarkan jasa serta belum memiliki peluang pengembangan kedepannya.

\section{HASIL DAN PEMBAHASAN}

\section{Analisis Potensi Desa Wisata Teritip yang Potensial untuk Dikembangkan Berdasarkan Daya Tarik yang Ada}

Berdasarkan hasil analisis ini diketahui faktor daya tarik yang potensial untuk dikembangkan menjadi pariwisata berbasis masyarakat. Dari proses pengkodean transkrip wawancara yang telah dilakukan didapatkan bahwa ketiga faktor daya tarik yang ada potensial untuk dikembangkan.

Tabel 1. Hasil pengkodean transkrip wawancara pada analisis konten

\begin{tabular}{|c|c|c|c|c|c|c|c|c|}
\hline $\begin{array}{l}\text { Faktor Daya } \\
\text { Tarik }\end{array}$ & R1 & $\mathrm{R} 2$ & R3 & R4 & R5 & R6 & $\mathrm{R} 7$ & Keterangan \\
\hline \multirow{2}{*}{$\begin{array}{l}\text { Keindahan } \\
\text { alam }\end{array}$} & $\mathrm{P}$ & $\mathrm{P}$ & $\mathrm{P}$ & $\mathrm{P}$ & $\mathrm{P}$ & $\mathrm{P}$ & $\mathrm{P}$ & \multirow[t]{2}{*}{ Konfirmasi } \\
\hline & $\begin{array}{l}\mathrm{T} 1.1, \\
\mathrm{~T} 1.2, \\
\mathrm{~T} 1.3, \\
\mathrm{~T} 1.8, \\
\mathrm{~T} 1.9, \\
\mathrm{~T} 1.10\end{array}$ & $\begin{array}{l}\text { T2.3, } \\
\text { T2.9 }\end{array}$ & $\begin{array}{l}\text { T3.1, } \\
\text { T3.2, } \\
\text { T3.3, } \\
\text { T3.4, } \\
\text { T3.5 }\end{array}$ & $\begin{array}{l}\mathrm{T} 4.1, \\
\mathrm{~T} 4.2, \\
\mathrm{~T} 4.3, \\
\mathrm{~T} 4.4, \\
\mathrm{~T} 4.5, \\
\mathrm{~T} 4.8, \\
\mathrm{~T} 4.9, \\
\mathrm{~T} 4.10, \\
\mathrm{~T} 4.11\end{array}$ & $\begin{array}{l}\text { T5.1, } \\
\text { T5.2, } \\
\text { T5.3, } \\
\text { T5.4, } \\
\text { T5.11, } \\
\text { T5.13, } \\
\text { T5.14 }\end{array}$ & $\begin{array}{l}\text { T6.1, } \\
\text { T6.2, } \\
\text { T6.5, } \\
\text { T6.6 }\end{array}$ & $\begin{array}{l}\text { T7.6, } \mathrm{T} 7.10, \\
\text { T7.12, } 77.16, \\
\text { T7.17, } \\
\text { T7.26, } \\
\text { T7.28 }\end{array}$ & \\
\hline \multirow{2}{*}{$\begin{array}{l}\text { Kegiatan } \\
\text { wisata }\end{array}$} & $\mathrm{P}$ & $\mathrm{P}$ & $\mathrm{P}$ & $\mathrm{P}$ & $\mathrm{P}$ & $\mathrm{P}$ & $\mathrm{P}$ & \multirow[t]{2}{*}{ Konfirmasi } \\
\hline & $\begin{array}{l}\text { T1.6, } \\
\text { T1.7, } \\
\text { T1.11 }\end{array}$ & $\begin{array}{l}\mathrm{T} 2.1, \\
\mathrm{~T} 2.2, \\
\mathrm{~T} 2.4, \\
\mathrm{~T} 2.6, \\
\mathrm{~T} 2.7, \\
\mathrm{~T} 2.8\end{array}$ & $\begin{array}{l}\text { T3.8, } \\
\text { T3.9, } \\
\text { T3.10, } \\
\text { T3.11, } \\
\text { T3.12 }\end{array}$ & $\begin{array}{l}\mathrm{T} 4.6, \\
\mathrm{~T} 4.7 \\
\mathrm{~T} 4.12 \\
\mathrm{~T} 4.13\end{array}$ & $\begin{array}{l}\text { T5.5, } \\
\text { T5.6, } \\
\text { T5.7, } \\
\text { T5.12 }\end{array}$ & $\begin{array}{l}\text { T6.3, } \\
\text { T6.7, } \\
\text { T6.8, } \\
\text { T6.9, } \\
\text { T6.10, } \\
\text { T6.12, } \\
\text { T6.13, } \\
\text { T6.14, } \\
\text { T6.15 }\end{array}$ & $\begin{array}{lr}\text { T7.1, } & \text { T7.2, } \\
\text { T7.3, } & \text { T7.5, } \\
\text { T7.7, } & \text { T7.8, } \\
\text { T7.9, } & \text { T7.11, } \\
\text { T7.13, } & \text { T7.15, } \\
\text { T7.18, } & \text { T7.19, } \\
\text { T7.20, } & \text { T7.21, } \\
\text { T7.22 } & \end{array}$ & \\
\hline \multirow{2}{*}{$\begin{array}{l}\text { Budaya } \\
\text { masyarakat }\end{array}$} & $\mathrm{P}$ & $\mathrm{P}$ & $\mathrm{P}$ & $\mathrm{P}$ & $\mathrm{P}$ & $\mathrm{P}$ & $\mathrm{P}$ & \multirow[t]{2}{*}{ Konfirmasi } \\
\hline & $\begin{array}{l}\mathrm{T} 1.4, \\
\mathrm{~T} 1.5\end{array}$ & $\mathrm{~T} 2.5$ & $\begin{array}{l}\text { T3.6, } \\
\text { T3.7 }\end{array}$ & $\begin{array}{l}\text { T4.14, } \\
\text { T4.15 }\end{array}$ & $\begin{array}{l}\text { T5.8, } \\
\text { T5.9, } \\
\text { T5.10 }\end{array}$ & $\begin{array}{l}\text { T6.4, } \\
\text { T6.11, } \\
\text { T6.16 }\end{array}$ & $\begin{array}{ll}\mathrm{T} 7.4, & \mathrm{~T} 7.14, \\
\mathrm{~T} 7.23, & \mathrm{~T} 7.24, \\
\mathrm{~T} 7.25 & \end{array}$ & \\
\hline \multicolumn{9}{|c|}{ Sumber: Hasil analisis, 2017} \\
\hline $\begin{array}{l}\text { Keterangan: } \\
\text { Kode Tx.y } \\
x=\text { urutan transk } \\
y=\text { urutan kutipc }\end{array}$ & $\begin{array}{l}\text { wawa } \\
\text { kalima }\end{array}$ & pada & $\begin{array}{l}\text { npiran } \\
\text { anskrip }\end{array}$ & \multicolumn{5}{|c|}{$\begin{array}{l}\mathrm{P}=\text { potensial untuk dikembangkan } \\
\mathrm{TP}=\text { tidak potensial untuk dikembangkan } \\
\text { Konfirmasi }=\text { ketujuh responden membahas tiap faktor } \\
\text { daya tarik dalam transkrip wawancara }\end{array}$} \\
\hline
\end{tabular}


Berikut penjelasan terkait uji validitas data di atas dengan membandingkan hasil wawancara dengan hasil observasi dan studi literatur.

\section{Keindahan alam}

Site attraction yang dimaksud adalah kondisi alam yang dimiliki suatu tempat yang menjadi daya tarik untuk kegiatan wisata. Adanya modal potensi alam ini merupakan salah satu faktor pendorong seseorang melakukan perjalanan wisata. Dilihat dari karakteristik wilayahnya, Desa Wisata Teritip memiliki karakteristik urban village atau desa perkotaan. Keindahan alam yang ditawarkan beragam mulai dari sawah, perkebunan, mangrove, tambak, hingga pantai yang membentang sepanjang pesisir Teritip. Mayoritas keindahan alam yang ada telah dimanfaatkan, walaupun belum optimal dalam pengelolaanya. Oleh karena itu, faktor keindahan alam yang tersedia di Desa Wisata Teritip potensial atau perlu dipertimbangkan dalam menentukan potensi yang prioritas untuk dikembangkan melalui pendekatan community-based tourism.

\section{Kegiatan wisata}

Event attraction merupakan kegiatan yang dilakukan di objek wisata alam karena dukungan dari kondisi alamnya dan menarik kedatangan pengunjung. Adanya kegiatan wisata dapat membuat wisatawan terkesan, baik berupa rasa puas maupun rasa nyaman dengan melihat ataupun ikut melaksanakannya. Keterlibatan wisatawan tersebut menimbulkan adanya interaksi antara wisatawan dengan masyarakat desa wisata. Timbulnya interaksi ini adalah suatu hal yang diharapkan dalam perencanaan desa wisata. Kegiatan wisata yang ada di Desa Wisata Teritip cukup beragam seperti menoreh karet, memanen hasil kebun dan sawah, membuat kerajinan tangan dan ukiran, membatik, ikut dalam aktivitas masyarakat sehari-hari, dan kegiatan lainnya. Beberapa kegiatan wisata yang ada telah menimbulkan interaksi antara wisatawan dengan masyarakat sebagai penyedia jasa. Berdasarkan penjabaran tersebut, faktor kegiatan wisata yang ada di Desa Wisata Teritip perlu dipertimbangkan dalam menentukan potensi yang prioritas untuk dikembangkan melalui pendekatan community- based tourism.

3. Budaya masyarakat

Salah satu komponen desa wisata adalah adanya budaya khas daerah setempat. Selain itu, untuk mendukung community-based tourism perlu menitikberatkan pada keberlanjutan sosial dan budaya yang dikelola dan dimiliki oleh masyarakat. Adanya potensi kebudayaan ini merupakan faktor pendukung dalam pengembangan desa wisata, dimana wisatawan atau pengunjung bisa tertahan dan dapat menghabiskan waktu di tengah masyarakat dengan kebudayaannya yang dianggap menarik. Di Desa Wisata Teritip tidak terdapat budaya turun-temurun. Akan tetapi, mulai dikembangkan budaya tarian untuk menyambut para wisatawan yang berkunjung. Adanya keberagaman multi etnik di Desa Wisata Teritip juga potensial untuk dikembangkan, terlebih masyarakat memiliki budaya keramahan dan kekeluargaan yang masih melekat. Oleh sebab itu, faktor budaya masyarakat di Desa Wisata Teritip perlu dipertimbangkan dalam menentukan potensi yang prioritas untuk dikembangkan melalui pendekatan community-based tourism.

\section{Identifikasi Potensi Wisata yang Prioritas untuk Dikembangkan melalui Pendekatan Community- Based Tourism}

Setelah didapatkan tiga faktor daya tarik yang potensial untuk dikembangkan, langkah selanjutnya yaitu mengklasifikasikan ketiga faktor tersebut dalam suatu komponen. Untuk faktor keindahan alam dikelompokkan dalam komponen fisik alam dan komponen objek wisata pendukung, sementara faktor budaya masyarakat 
dikelompokkan dalam komponen sosial budaya/living culture. Sementara faktor kegiatan wisata tidak dikategorikan dalam suatu komponen karena mampu dihasilkan dari pemanfaatan dua lainnya dan menjadi salah satu penilaian dalam penentuan potensi wisata yang prioritas untuk dikembangkan. Selain identifikasi kegiatan wisata, dalam penentuan potensi prioritas juga mempertimbangkan peluang pengembangan yang ada di tiap potensi berdasarkan hasil wawancara stakeholders. Berikut penjabaran hasil identifikasi potensi wisata yang prioritas untuk dikembangkan melalui pendekatan community-based tourism.

Tabel 2. Identifikasi potensi wisata Desa Wisata Teritip yang prioritas untuk dikembangkan melalui pendekatan Community-Based Tourism

\begin{tabular}{|c|c|c|c|c|c|}
\hline Komponen & \multicolumn{2}{|c|}{ Potensi Daya Tarik } & $\begin{array}{l}\text { Kegiatan yang } \\
\text { Telah } \\
\text { Ditawarkan }\end{array}$ & $\begin{array}{l}\text { Peluang yang Dapat } \\
\text { Dikembangkan }\end{array}$ & Keterangan \\
\hline \multirow[t]{12}{*}{ Fisik/Alam } & $\begin{array}{l}\text { Potensi } \\
\text { pertanian }\end{array}$ & Tanaman padi & $\begin{array}{l}\text { Atraksi } \\
\text { menanam dan } \\
\text { memanen padi } \\
\text { biasa }\end{array}$ & $\begin{array}{l}\text { Atraksi menanam dan } \\
\text { memanen padi jenis baru yaitu } \\
\text { padi hitam }\end{array}$ & Prioritas \\
\hline & \multirow[t]{6}{*}{$\begin{array}{l}\text { Potensi } \\
\text { perkebunan }\end{array}$} & Karet & $\begin{array}{l}\text { Atraksi } \\
\text { menyadap } \\
\text { getah }\end{array}$ & Atraksi mengolah getah karet & Prioritas \\
\hline & & Cabai & ( & $\begin{array}{l}\text { Budidaya tanaman cabai agar } \\
\text { menjadi salah satu objek } \\
\text { agrowisata }\end{array}$ & $\begin{array}{l}\text { Tidak } \\
\text { Prioritas }\end{array}$ \\
\hline & & $\begin{array}{l}\text { Tanaman } \\
\text { sayur lain: } \\
\text { buncis, } \\
\text { kacang } \\
\text { panjang, } \\
\text { sawi, terong }\end{array}$ & - & $\begin{array}{l}\text { Meningkatkan produktivitas } \\
\text { berbagai tanaman holtikultura } \\
\text { ini agar memiliki nilai jual } \\
\text { lebih }\end{array}$ & $\begin{array}{l}\text { Tidak } \\
\text { Prioritas }\end{array}$ \\
\hline & & Pepaya mini & $\begin{array}{l}\text { Kegiatan } \\
\text { memetik buah }\end{array}$ & $\begin{array}{l}\text { Atraksi mengolah pepaya mini } \\
\text { menjadi manisan, abon, } \\
\text { pestisida, dan lainnya }\end{array}$ & Prioritas \\
\hline & & Salak & $\begin{array}{l}\text { Kegiatan } \\
\text { memetik buah }\end{array}$ & Atraksi mengolah dodol salak & Prioritas \\
\hline & & $\begin{array}{l}\text { Buah naga, } \\
\text { nangka, } \\
\text { cempedak, } \\
\text { durian, } \\
\text { rambutan, } \\
\text { duku }\end{array}$ & - & Atraksi memetik buah & $\begin{array}{l}\text { Tidak } \\
\text { Prioritas }\end{array}$ \\
\hline & \multirow[t]{2}{*}{$\begin{array}{l}\text { Potensi } \\
\text { pertambakan }\end{array}$} & Kepiting soka & $\begin{array}{l}\text { Kegiatan } \\
\text { budidaya }\end{array}$ & Atraksi pengolahan kepiting & Prioritas \\
\hline & & $\begin{array}{l}\text { Udang dan } \\
\text { bandeng }\end{array}$ & - & - & $\begin{array}{l}\text { Tidak } \\
\text { Prioritas }\end{array}$ \\
\hline & $\begin{array}{l}\text { Potensi } \\
\text { peternakan }\end{array}$ & $\begin{array}{l}\text { Ayam dan } \\
\text { sapi }\end{array}$ & - & Atraksi pembuatan pupuk & $\begin{array}{l}\text { Tidak } \\
\text { Prioritas }\end{array}$ \\
\hline & \multicolumn{2}{|c|}{ Landscape perbukitan } & - & $\begin{array}{l}\text { Kegiatan berkemah, outbound, } \\
\text { dan bersepeda }\end{array}$ & $\begin{array}{l}\text { Tidak } \\
\text { Prioritas }\end{array}$ \\
\hline & Pantai & Rumput laut & - & $\begin{array}{l}\text { Atraksi menanam, memanen, } \\
\text { dan mengolah rumput laut }\end{array}$ & $\begin{array}{l}\text { Tidak } \\
\text { Prioritas }\end{array}$ \\
\hline
\end{tabular}


Tabel 3. Lanjutan

\begin{tabular}{|c|c|c|c|c|}
\hline Komponen & Potensi Daya Tarik & $\begin{array}{l}\text { Kegiatan yang } \\
\text { Telah } \\
\text { Ditawarkan }\end{array}$ & $\begin{array}{l}\text { Peluang yang Dapat } \\
\text { Dikembangkan }\end{array}$ & Keterangan \\
\hline $\begin{array}{l}\text { Sosial } \\
\text { Budaya/ } \\
\text { Living } \\
\text { Culture }\end{array}$ & $\begin{array}{l}\text { Keragaman multi etnik (Jawa, } \\
\text { Bugis, Banjar, Dayak dan } \\
\text { Melayu) }\end{array}$ & $\begin{array}{l}\text { Tari-tarian dan } \\
\text { pembuatan } \\
\text { makanan khas } \\
\text { dan kue } \\
\text { tradisional }\end{array}$ & $\begin{array}{l}\text { Menghias homestay sesuai } \\
\text { etnis } \\
\text { Atraksi kesenian daerah dari } \\
\text { berbagai etnis. } \\
\text { Komedi tradisional } \\
\text { Mengadakan event budaya }\end{array}$ & Prioritas \\
\hline \multirow[t]{6}{*}{$\begin{array}{l}\text { Objek } \\
\text { Wisata } \\
\text { Pendukung }\end{array}$} & $\begin{array}{ll}\text { Kebun } & \text { Bukit } \\
\text { Penelitian } & \text { pringgondani } \\
\text { Bukit } & 1 \\
\text { Pringgondani } & \end{array}$ & $\begin{array}{l}\text { Wisata edukasi } \\
\text { Atraksi } \\
\text { membatik dan } \\
\text { pembuatan } \\
\text { kerajinan } \\
\text { tangan }\end{array}$ & $\begin{array}{ll}\text { Pembangunan } & \text { sarana } \\
\text { permainan anak } & \end{array}$ & Prioritas \\
\hline & $\begin{array}{l}\text { Bukit } \\
\text { pringgondani } \\
2 \\
\end{array}$ & Demplot gaharu & $\begin{array}{l}\text { Usaha olahan gaharu, seperti } \\
\text { teh, kopi, sabun, dan lainnya }\end{array}$ & Prioritas \\
\hline & $\begin{array}{lll}\text { Objek Wisata Penangkaran } \\
\text { Buaya }\end{array}$ & $\begin{array}{lr}\text { Atraksi } & \text { foto } \\
\text { bersama } & \text { anak } \\
\text { buaya. } & \\
\end{array}$ & Atraksi pertunjukan buaya & Prioritas \\
\hline & Mangrove DPML Teritip & - & $\begin{array}{l}\text { Kegiatan berkunjung ke } \\
\text { mangrove DPML }\end{array}$ & $\begin{array}{l}\text { Tidak } \\
\text { Prioritas }\end{array}$ \\
\hline & $\begin{array}{l}\text { Pemancingan Lembah Geger } \\
\text { kalong dan Pondok Bambu }\end{array}$ & $\begin{array}{l}\text { Kegiatan } \\
\text { memancing }\end{array}$ & $\begin{array}{l}\text { Jasa memasak dan penyewaan } \\
\text { penginapan }\end{array}$ & Prioritas \\
\hline & Pesantren Hidayatullah & - & Kegiatan wisata religi & $\begin{array}{l}\text { Tidak } \\
\text { Prioritas }\end{array}$ \\
\hline
\end{tabular}

Sumber: Hasil Analisis, 2017

Dari tabel di atas dapat dilihat bahwa tidak semua potensi daya tarik yang ada mampu menghasilkan kegiatan wisata maupun memiliki peluang pengembangan kedepan sehingga hanya beberapa potensi saja yang prioritas atau diutamakan untuk dikembangkan dengan pendekatan community-based tourism.

\section{KESIMPULAN DAN REKOMENDASI}

Berdasarkan hasil analisis dan pembahasan yang telah dilakukan maka dapat ditarik kesimpulan sebagai berikut.

1. Daya tarik Desa Wisata Teritip yang potensial untuk dikembangkan menjadi community-based tourism adalah keindahan alam dan budaya masyarakat serta kegiatan wisata yang dapat diciptakan dengan pemanfaatan keduanya.

2. Potensi daya tarik wisata yang prioritas untuk dikembangkan dengan mengutamakan peran masyarakat lokal, antara lain (a) komponen fisik/alam, meliputi potensi pertanian: tanaman padi, potensi perkebunan: karet, pepaya mini, dan salak, serta potensi pertambakan: kepiting soka; (b) komponen sosial budaya/living culture, yaitu keragaman multi etnik masyarakat lokal; serta (c) komponen objek wisata pendukung, meliputi kebun penelitian: Kebun Pringgondani 1 dan 2, Objek Wisata Penangkaran Buaya serta pemancingan Lembah Gegerkalong dan Pondok Bambu.

Rekomendasi dalam penelitian ini adalah diperlukan penerapan metode partisipatif dari masyarakat lokal yang dimulai sejak saat ini karena melihat perkembangan Desa Wisata Teritip yang belum optimal jika dilihat dari potensi wisata yang belum termanfaatkan sepenuhnya dan atraksi yang dihasilkan masih terbatas. Metode partisipatif ini digunakan untuk memudahkan pengoptimalan sumber daya desa yang dapat diawali dengan upaya identifikasi potensi dan permasalahan yang dimiliki Desa Wisata Teritip dengan keterlibatan masyarakat lokal karena mereka dianggap mengetahui tentang 
keperluan atau kebutuhan untuk pengembangan desanya. Rekomendasi ini bertujuan untuk mengembangkan Desa Wisata Teritip dengan pendekatan yang tepat yaitu bottom up planning sehingga setelah masyarakat lokal mampu mengenali potensi wilayahnya, diharapkan akan mempermudah langkah pengembangan desa kedepannya.

\section{UCAPAN TERIMA KASIH}

Penulis K.A.P. mengucapkan terima kasih kepada Ibu Ajeng Nugrahaning Dewanti, S.T., M.T., yang telah membimbing peneliti hingga mampu menyelesaikan penelitian ini hingga akhir serta kepada pihak-pihak terkait yang bersedia menjadi sumber dan/atau responden dalam membantu penelitian ini.

\section{DAFTAR PUSTAKA}

Adisasmita, R. (2013). Pembangunan Perdesaan Pendekatan Partisipatif Tipologi Strategi dan Konsep Desa Pusat Pertumbuhan. Yogyakarta: Graha Ilmu.

Astuti, S. K. (2012). Dampak Sosio Kultural Masyarakat Dusun Krebet Sebagai Salah Satu Destinasi Wisata Perdesaan. Skripsi. Universitas Negeri Yogyakarta.

Beeton, S. (2006). Community Development through Tourism. Australia: Landlinks Press.

Ikhwanuddin. (2015). Analisis Konsep Desain Hybrid pada Masjid Agung Jawa Tengah (Tinjauan Aspek Ruang dan Bentuk). Jurnal NALARs, 10(1), 1-16.

Mujanah, S., Ratnawati, T., dan Andayani, S. (2016). Strategi Pengembangan Desa Wisata di Kawasan Hinterland Gunung Bromo Jawa Timur. Jurnal Hasil Penelitian LPPM Untag Surabaya, 1(1), 33-52.

Nurdiyanto, S. (2015). Partisipasi Masyarakat dalam Pengembangan Desa Wisata (Studi di Desa Wisata Bleberan, Kecamatan Playen, Kabupaten Gunungkidul). Skripsi. Universitas Islam Negeri Sunan Kalijaga.

Purmada, D. K., Wilopo, \& Hakim, L. (2016). Pengelolaan Desa Wisata dalam Perspektif Community Based Tourism (Studi Kasus pada Desa Wisata Gubugklakah, Kecamatan Poncokusumo, Kabupaten Malang). Jurnal Administrasi Bisnis, 32(2), 15-22.
Rahayu, S., Dewi, U., \& Fitriana, K.N. (2015). Pengembangan Pariwisata Berbasis Masyarakat (Community Based Tourism) di Kabupaten Kulon Progo Daerah Istimewa Yogyakarta. Laporan Penelitian Hibah Bersaing, Universitas Negeri Yogyakarta.

Suhamdani, H. (2013). Analisis Pengembangan Pariwisata Alam Lewaja di Kabupaten Enrekang. Skripsi. Universitas Hasanuddin.

Susyanti, D. W. (2013). Potensi Desa Wisata Melalui Pariwisata Pedesaan. Jurnal Ekonomi dan Bisnis, 12(1), 33-36. 